\title{
Laser Processing in Industrial Solar Module Manufacturing
}

\author{
Heather BOOTH \\ Oerlikon Solar Ltd, Trubbach, Hauptstrasse 1a, 9477 Trubbach, Switzerland \\ E-mail: heather.booth@oerlikon.com
}

\begin{abstract}
The use of lasers in the processing of solar cell structures has been known for many years both for c-Si and thin-film solar technologies. The maturity of the laser technology, the increase in scale of solar module production and the pressures to drive down cost of ownership and increase cell efficiencies have all contributed to the adoption of laser processes in industrial manufacturing. Today laser systems are the tool of choice in thin-film module manufacturing both for scribing the cell interconnects and for the module edge isolation. For c-Si solar cells the primary laser application today is edge isolation and this is well-established in industrial production of most types of waferbased cells. Other laser processes are used in the production of advanced high-efficiency c-Si cell designs such as laser grooved buried contacts, emitter wrap-through or metal wrap-through interconnects, selective emitters and laser fired contacts. In the mission of the solar industry to reduce the cost of electricity generation there are increasing opportunities for laser processing to contribute to the goal of low cost of ownership in industrial manufacturing through improved module efficiencies, higher throughput and reduced process costs.

DOI:10.2961/jlmn.2010.03.0001
\end{abstract}

Keywords: laser processing, laser scribing, photovoltaic, thin-film, edge isolation, EWT, MWT.

\section{Introduction}

The growth of the photovoltaics (PV) industry has been dramatic in the past few years, from just under $2.4 \mathrm{GW}$ in 2007 to over $6 \mathrm{GW}$ in 2009 [1]. This growth this largely been driven by the demand for electricity providers to include renewable energy generation in their portfolio and the economic policies of many nations providing subsidies for the production of modules and electricity generation using PV.

The growth of PV module production in recent years has been coupled with a dramatic reduction in the sales price of complete modules, current prices from China average at $1.81 \$ / \mathrm{Wp}$ for poly-c-Si based modules and $1.21 \$ / \mathrm{Wp}$ for thin-film a-Si modules compared with $4 \$ / \mathrm{Wp}$ and $2 \$ / \mathrm{Wp}$ respectively in 2008 [2].

This increasing demand for PV modules also lead to a rapid expansion in the equipment market for PV module production including laser tools for PV cell manufacturing. The equipment spending showed high growth from $\$ 1,000 \mathrm{M}$ in 2005 to over $\$ 7,000 \mathrm{M}$ in 2008 [3]. This spending then stabilized in 2009 at just under $\$ 6,000 \mathrm{M}$ and is predicted to remain at that level for the next couple of years. One reason for this is that equipment supplied in 2008 is not yet at full capacity and has reduced the demand for new equipment. The other reason is the drive to meet market price pressures has lead to module manufacturers striving for higher efficiencies whilst maintaining high throughput and low cost manufacturing, hence more MWs can be produced with the same equipment at lower cost.

Incremental improvements in module efficiency impact the cost of electricity in a number of ways: higher efficiency means fewer modules are required to produce the same amount of electricity; the smaller footprint required costs less; and there are also lower balance of system
(BOS) and installation costs.

The market drive to reduce the cost of solar energy has lead to a decreasing fraction of production from standard cSi wafer-based cell types [4]. Thin-film cells offer lower cost and high-efficiency (HE) c-Si cells offer higher conversion efficiencies, both are increasing in market share. Lasers feature in many important manufacturing process steps in both technology areas

\section{Thin-film modules}

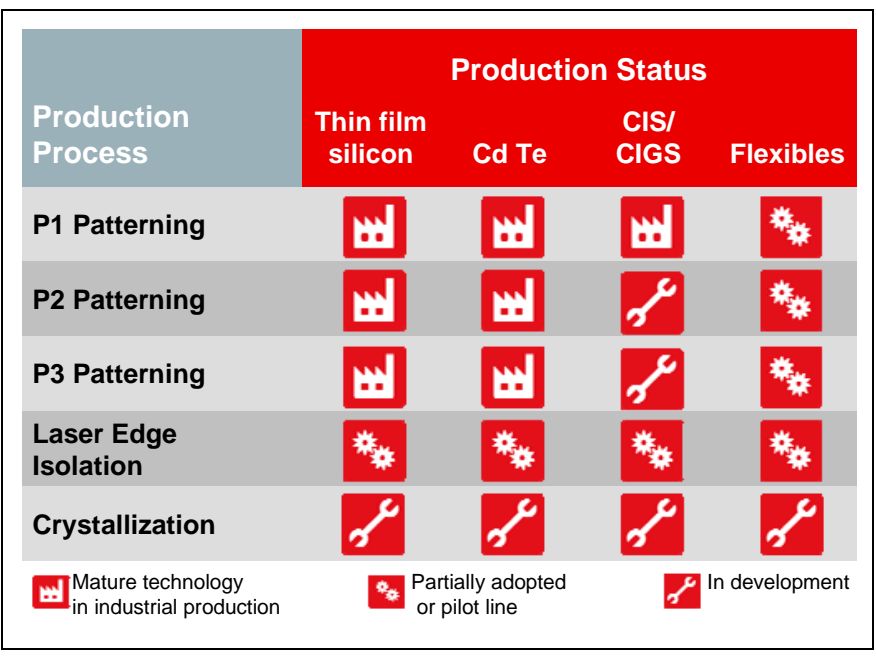

Table 1 Laser processes for thin-film PV and status for industrial production.

Laser processing is the method of choice for many processes in thin-film module manufacturing. The overview of laser processes in thin-film PV and their relative adoption to industrial production is shown in Table 1. La- 
ser processing has been adopted by most of the PV cell technologies both for scribing the cell interconnect pattern and for the module edge isolation. Laser crystallization to enhance the efficiency of the absorber layer however is a relatively immature technology and has yet to show the cost of ownership advantage required for adoption to mainstream industrial production.

\subsection{Thin-film P1, P2 and P3 patterning}

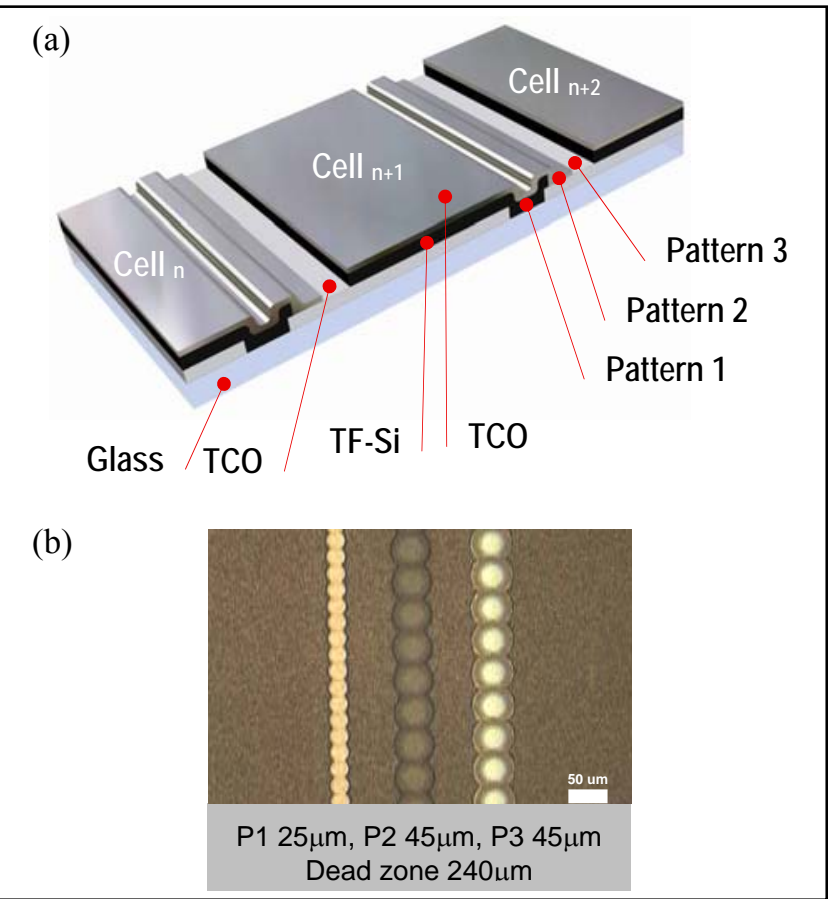

Fig. 1 Thin-film silicon module (a) interconnection schematic and (b) microscope image of typical Oerlikon Solar production $\mathrm{P} 1, \mathrm{P} 2$ and $\mathrm{P} 3$ scribe patterns.

Thin-film PV panels require sectioning into multiple cells which are connected in series, otherwise they would form low voltage, high current devices with very high ohmic losses. Typically the panels are sectioned into one hundred cells or more to achieve suitable current voltage characteristics. This involves multiple coating and subsequent patterning steps. In the case of Oerlikon Solar's thinfilm silicon panels the transparent conductive oxide (TCO) film of zinc oxide is deposited on the glass substrate as the front contact of the device. This is sectioned into approximately 100 parallel cells using a $355 \mathrm{~nm}$ nanosecondpulsed DPSS laser applied through the glass substrate to remove the layer in a single shot process. The pattern 1 (P1) scribe lines thus formed isolate the front contact between the cells. The absorber layer of amorphous silicon or amorphous and microcrystalline silicon for a micromorph tandem cell is then deposited. This is followed by the pattern 2 (P2) laser process which uses a $532 \mathrm{~nm}$ nanosecond-pulsed DPSS laser applied through the glass to selectively remove the silicon layer from the top of the front contact TCO in a single shot process. The P2 scribe line forms the interconnection between the subsequently deposited back contact and the front contact TCO. The pattern 3 (P3) is scribed using a $532 \mathrm{~nm}$ nanosecond pulsed-laser applied through the glass to selectively remove the absorber and back contact TCO layers from the top of the front contact $\mathrm{TCO}$ in a single shot process. The scribes thus formed isolate the $\mathrm{BC}$ of the cells and complete the serial connection of the cells in the panel. Pulse energies for the scribing processes are in the range of 5-15 $\mu \mathrm{J}$ with lasers operating between 30 and $90 \mathrm{kHz}$.

The resulting scribe interconnection pattern is depicted in Fig. 1(a) and a picture of the resulting scribes from an Oerlikon Solar production line is shown in Fig. 1(b). Although a $1064 \mathrm{~nm}$ laser is commonly used to process P1 for tin oxide front contacts, for zinc oxide layers this wavelength does not provide the required scribe isolation and quality, so UV processing is required. There is also the added advantage of narrower scribe width for the same depth of focus with UV compared to IR which enables a narrower dead zone to be achieved, as shown in Fig. 1.

Cadmium Telluride (CdTe), Copper Indium Selenide (CIS) and Copper Indium Gallium Selenide (CIGS) modules have a similar structure to that described above, namely glass substrate, conductor, absorber and conductor. All thin-film technologies require P1, P2 and P3 serial interconnection, however the optimum laser processes differ both in the laser types used and whether the laser is applied through the glass or from the layer side.

For CdTe thin-film modules such as those supplied by First Solar, the P1 process is performed with an infra-red nanosecond-pulsed DPSS laser through the glass to remove both the front contact TCO and absorber layers after their deposition. This $\mathrm{P} 1$ scribe is then filled with a dielectric and the P2 scribe performed with the same laser at lower energy to the P1 process to remove the absorber layers without removing the front contact TCO. The metallic back contact is then deposited and the P3 scribe patterned with the same laser and even lower energy to remove the back contact leaving the absorber intact, thus completing the serial connection between the cells [5].

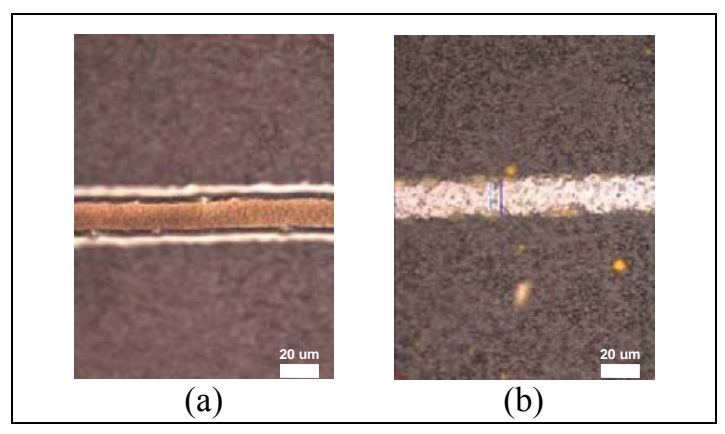

Fig. 2 Picosecond laser scribes in CIGS, processed from the layer side; (a) P2 and (b) P3 (images courtesy of Trumpf).

For CIS and CIGS modules lasers are widely used for P1 processes, however P2 and P3 processes are typically processed using mechanical scribing tools. One of the main reasons for this is that the metallic back contact is deposited on the glass substrate first and forms the broadband reflective layer at the rear surface of the module. The absorber and front contact TCO layers are then deposited on top and hence these layers must be processed from the layer side to prevent damage to the metallic back contact. These P2 and P3 processes are possible with ultra-shortpulse lasers [6], typically picosecond, however adoption is limited due to the immature process and higher cost of 
ownership which is typically $2 \mathrm{x}$ a typical nanosecond laser scribing process. Examples of P2 and P3 scribes in CIGS processed with a green picosecond laser from the layer side are shown in Fig. 2. Typical processing parameters are 10 's $\mu \mathrm{J}$ at 10 's $\mathrm{kHz}$ depending on the specific layer properties.

\subsection{Laser scribe properties and module power}

Laser processing offers a non contact, clean scribe patterning process with repeatable properties which is ideal for the segmentation and interconnection of thin-film modules. However, the area that the scribe patterns occupy on the modules is not active and cannot contribute to electricity generation in the module. Therefore, it is imperative that the laser tool used has a high accuracy for the scribe positioning to allow good alignment between laser scribe patterns to minimize the laser 'dead zone' and to maximize the active area of the module and hence the module power. The scribe process must include alignment of successive patterns P1, P2 and P3 to each other and also deal with temperature changes in the panels between coating steps. In some cases this includes active alignment during scribing patterns P2 and P3. The percentage area occupied by a varying laser scribe dead zone width is illustrated in Fig. 3. To take the reference of an Oerlikon Solar amorphous panel with stabilized power of $95 \mathrm{~W}$ and production dead zone of $240 \mu \mathrm{m}$, improvement to $200 \mu \mathrm{m}$ would add $0.5 \%$ active area and hence power, equivalent to $0.5 \mathrm{~W}$. In comparison to other producers with scribe dead zones up to $500 \mu \mathrm{m}$, this represents a drop of $4 \%$ or $4 \mathrm{~W}$. For micromorph panels, there are fewer cells and the impact on the power is lower. With reference to an Oerlikon Solar $125 \mathrm{~W}$ micromorph module with production dead zone of $240 \mu \mathrm{m}$, improvement to $200 \mu \mathrm{m}$ would add $0.5 \mathrm{~W}$ and for others at $500 \mu \mathrm{m}$ this would represent a drop of $2.5 \%$ or $3 \mathrm{~W}$.

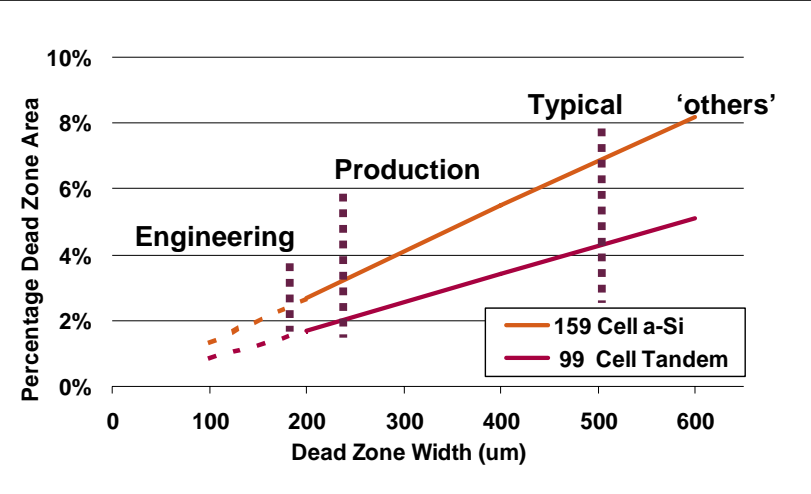

Fig. 3 Effect of laser dead zone on active area for a Oerlikon Solar amorphous and micromorph tandem modules.

In addition to accurate scribe positioning, the laser process must deliver good scribe performance. This means good isolation with P1 and P3 with no missing laser shots and a low number of shunts, characterised by high module parallel resistance $\left(\mathrm{R}_{\mathrm{p}}\right)$. It also means good interconnection by $\mathrm{P} 2$ with clean removal of layers, characterised by low module serial resistance $\left(R_{s}\right)$. It is also important for device integrity that there is no damage to glass in the case of $\mathrm{P} 1$, or in the case of P2 and P3 the underlying coating layers. The impact of shunts on module power can vary greatly depending on the type of shunts, however with Oerlikon Solar's Micromorph modules, using a zinc oxide back contact, typically it takes about 40 isolated shunts to have a $1 \mathrm{~W}$ impact on module power. For a module which uses a metal back contact, the impact on power can be considerably increased due to the lower resistance of the contact which means a larger area of the module is affected by any one shunt.

\subsection{Laser edge isolation}

Laser processing is increasingly being used by thin-film manufacturers to delete the border region of the module and provide the required electrical isolation of the active area from the edge of the module, see Fig. 4(a). This process is known as laser edge isolation or edge deletion. It requires accurate removal of all coating materials to give good isolation and to leave a high quality remaining surface with low surface roughness and no glass damage or micro-cracking to ensure good lamination and high module reliability. The laser process is similar for all thin-film technologies and uses a high power, typically 400-1000 W at $5-15 \mathrm{kHz}$, infra-red nanosecond-pulsed DPSS laser delivered via optical fiber to form square top-hat beam of approximately $800 \mu \mathrm{m}$ at the panel. The processing is performed through the glass with fast motion of the beam using a galvo-scanner and constant motion of the panel to cover the edge regions.

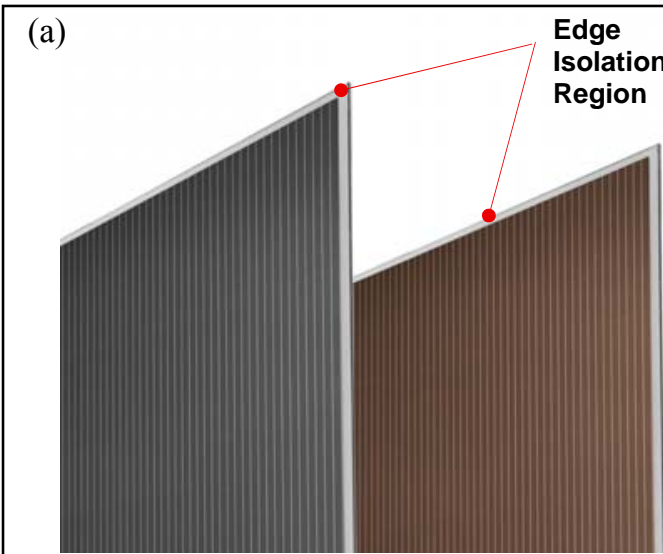

(b)

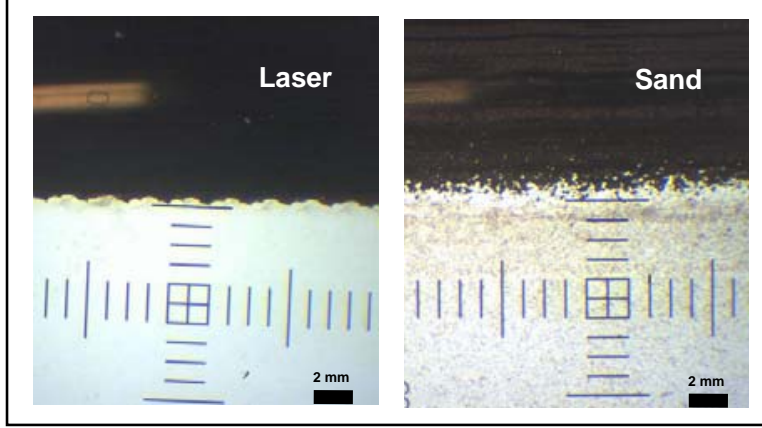

Fig. 4 Edge isolation of a thin-film module (a) isolated border region of thin-film silicon modules, (b) edge isolation with laser and sand blasting (courtesy of 4-Jet).

Laser systems deliver a non-contact, clean edge isolation process and the accurate shot positioning and well defined edge allows close alignment to laser scribe pattern and helps maximize active area. Typically the remaining 
surface has no glass damage and no micro-cracks; it is important that the layers are removed without altering the glass surface properties providing a good basis for lamination. The isolation achieved is $>11 \mathrm{G} \Omega / \mathrm{mm}$ at $1 \mathrm{kV}$ and laminated modules meet requirements for electrical isolation and module lifetime tests. The alternate technology in production today involves 'sand-blasting' the edge region using an abrasive jet. A comparison of the edge quality achieved with the two technologies is shown in Fig. 4(b). It can be seen that the sand-blasting leaves more material on the active area of the panel for up to $3 \mathrm{~mm}$ next to the border region which means that the scribe pattern cannot be placed as near to the ablated region as with the cleaner laser edge isolation process.

\subsection{Industrial processing of thin-film modules}

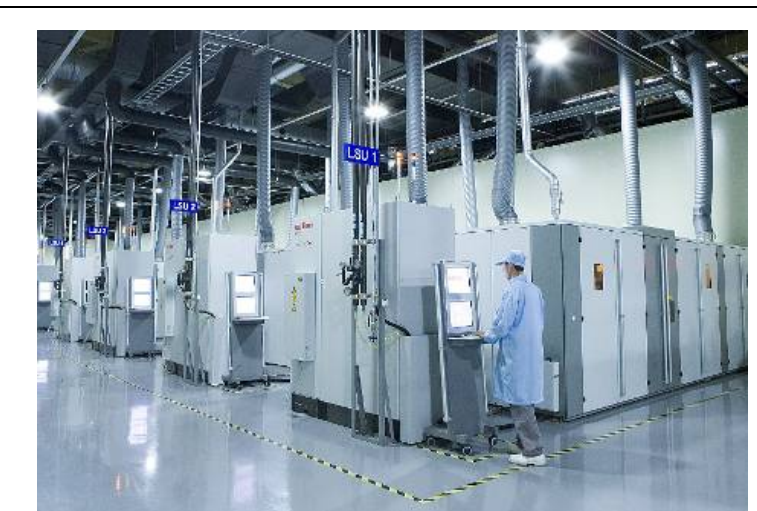

(a)

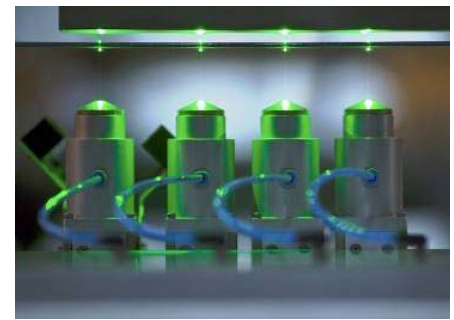

(b)

Fig. 5 Thin-film industrial laser scribing equipment (a) Oerlikon Solar's LSS1200 in end-to-end production line, (b)

Multiple laser beams for scribing with high throughput.

As mentioned previously, laser processing is a wellestablished technology for patterning of thin-film modules. For example, the LSS1200 laser scribe tools from Oerlikon Solar (Fig. 5) have been in serial manufacturing since 2006 with over 80 tools today in production. The tools scribe P1, $\mathrm{P} 2$, and P3 in the same platform and utilize multiple beams in the processing to give high throughput. The good stability of performance over time and high reproducibility tool to tool allow fabs to run in production with a laser scribe dead zone of less than $240 \mu \mathrm{m}$.

\section{Crystalline silicon wafer based cells}

Laser processing in c-Si wafer-based modules is in general not as well established as in thin-film PV technologies. The overview of laser processes in c-Si wafer-based PV and their relative adoption to industrial production is shown in Table 2. Laser edge isolation has been used in the production of most types of 'standard' wafer based cells for some years, but it has not been adopted everywhere as plasma etch and chemical etch processes are also possible. Laser cutting is used in industrial production for resizing of wafers or singulation of cells for concentrator PV cells in relatively low volumes.

\begin{tabular}{|c|c|}
\hline Production Process & $\begin{array}{c}\text { Production Status } \\
\text { C-Si Cells }\end{array}$ \\
\hline Laser Edge Isolation & 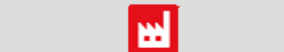 \\
\hline Laser Grooved Buried Contacts (LGBC) & 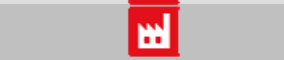 \\
\hline Cutting/ Singulation & $\omega$ \\
\hline $\begin{array}{l}\text { Emitter Wrap-Through (EWT) and Metal } \\
\text { Wrap-Through (MWT) Interconnects }\end{array}$ & *** \\
\hline Selective Emitters (SE) Ablation & * \\
\hline Selective Emitters (SE) Dopant Diffusion & * \\
\hline Laser Fired Contacts (LFC) & \\
\hline Interconnection/ soldering & \\
\hline Texturing & \\
\hline 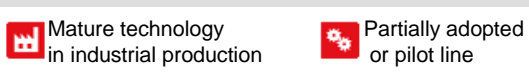 & $\nearrow^{\text {In development }}$ \\
\hline
\end{tabular}

Table 2 Laser processes for c-Si wafer based PV and status for industrial production.

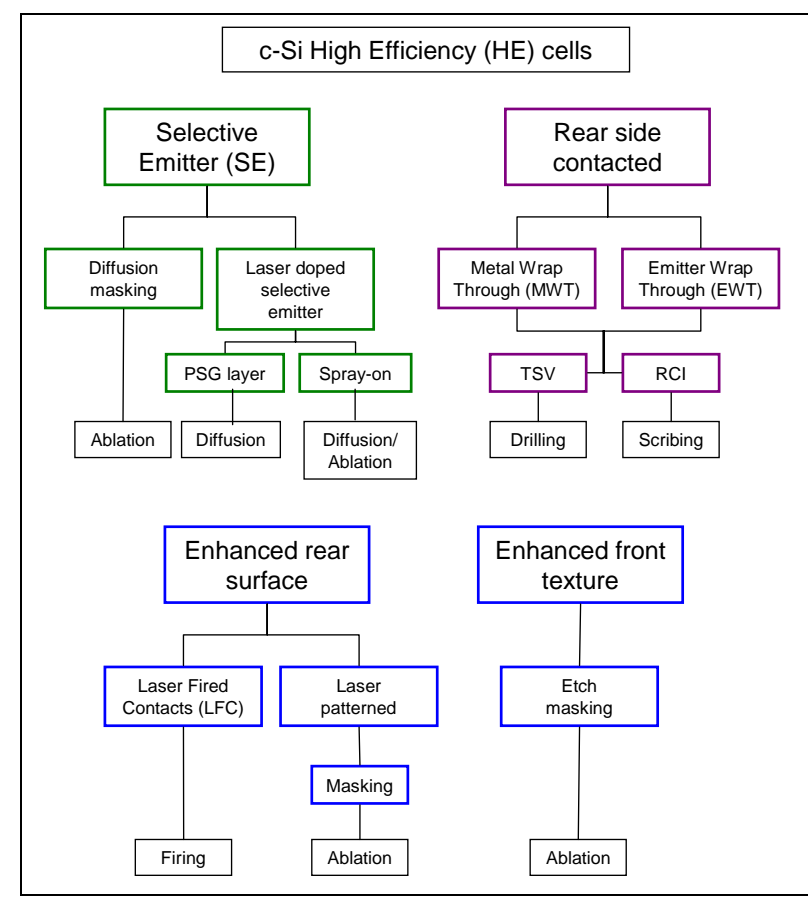

Fig. 6 Overview of laser processes enabling c-Si high efficiency cells (ablation, diffusion, scribing, drilling, firing), adapted from [4].

There is an increasing share of PV production constituted by the higher efficiency (HE) c-Si cell types, a large proportion of which are enabled by lasers in some way [4] Features which are used in the production of advanced HE cell designs are laser grooved buried contacts (LGBC), selective emitters (SE) on the front side of the wafer or laser fired contacts (LFC) on the rear side of the wafer and emitter wrap-through (EWT) or metal wrap-through (MWT) interconnects from the front side to the rear side of 
the wafer. The laser processes which contribute to the production of HE cells are depicted in Fig. 6; these will be discussed in more detail in the following sections.

The processes of laser soldering of contacts and laser texturing for enhancing cell efficiencies are in the development stage today.

\subsection{Laser edge isolation}

The production of conventional or standard c-Si solar cells involves a p-type poly-crystalline silicon wafer which is textured then diffused over the entire surface with n-type phosphorous. After etching an anti-reflective silicon nitride layer is applied and the front contacts are screen printed with silver paste. Firing of the contacts melts them through the SiN layer to contact the n-type silicon. The rear planar contact is plated with aluminium. A schematic of such a cell is shown in Fig. 7(a).

The edge isolation process typically uses a galvoscanner to scribe a continuous groove of width approximately $70 \mu \mathrm{m}$ and depth $10-20 \mu \mathrm{m}$ around the edge of the wafer, see Fig. 7(a). The groove extends below the doped silicon into the underlying p-type silicon and isolates the diffused front junction from the edge of the cell to remove shunt pathways to the rear contact. Historically, infra-red nanosecond-pulsed DPSS lasers have been used for the process, but increasingly green or UV lasers are being implemented due to their shorter absorption depth in the silicon and ability to scribe narrower $(20 \mu \mathrm{m})$ grooves without micro-cracking [7], [8]. A typical groove produced with a UV laser is shown in Fig. 7(b). The industrial cycle time per wafer is less than 1 second with laser powers in excess of $20 \mathrm{~W}$, repetition rates of $\sim 100 \mathrm{kHz}$ and pulsewidths of $\sim 25 \mathrm{~ns}$.

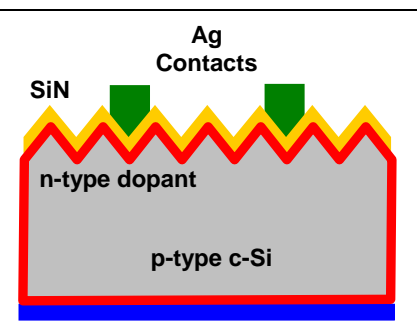

Al back contact

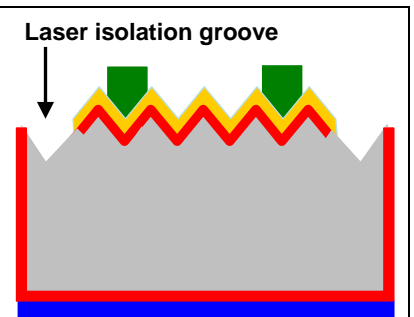

(a)

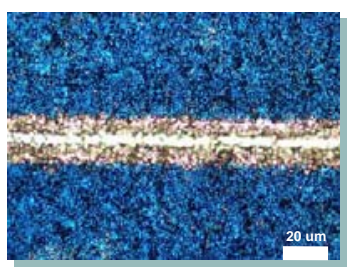

(b)

Fig. 7 Laser edge isolation of c-Si cells. (a) Schematic of standard c-Si wafer based cell with laser isolation. (b) Microscope image of laser scribe (courtesy of Coherent).

\subsection{Laser grooved buried contacts (LGBC)}

Laser grooved buried contact cells were developed by the University of New South Wales and employed by BP Solar [9], [10], see Fig. 8. This early high-efficiency cell design used infra-red nanosecond lasers to scribe an array of contact grooves in high quality mono-crystalline wafers. The grooves were etched and 'double' doped to give a more heavily doped region below the conductors, then electroless plated to form deep narrow contacts. This allowed optimization of the doping characteristics; heavy doping to provide low contact resistance and minimize resistance losses as collected current flows to the contacts, and low doping between the contacts to reduce recombination losses. This enabled HE cells to be produced approaching 20\% efficiency [11]. Although BP Solar's LGBC Saturn cells are unfortunately no longer in production, they did pave the way for a new generation of $\mathrm{HE}$ cells based on the selective emitter technologies discussed below.

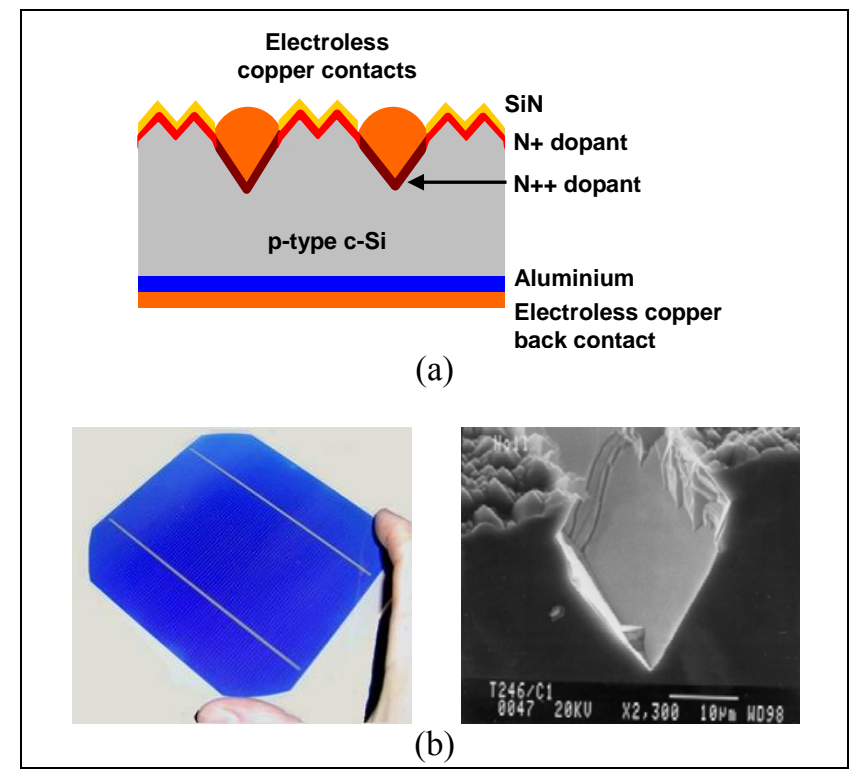

Fig. 8 (a) Schematic LGBC cell. (b) Photograph of LGBC cell and microscope picture of laser groove after etching (courtesy of Exitech).

3.3 Laser processed elective emitters (SE) and contacts Laser processed selective emitters (SE) can be used to facilitate narrow front contacts with high aspect ratio and strong doped areas below for good electrical contact and current collection [12]. There are various methods reported which use lasers to produce the fine array of contacts on the front surface of the wafer creating a SE structure [13], two of which are described in detail below.

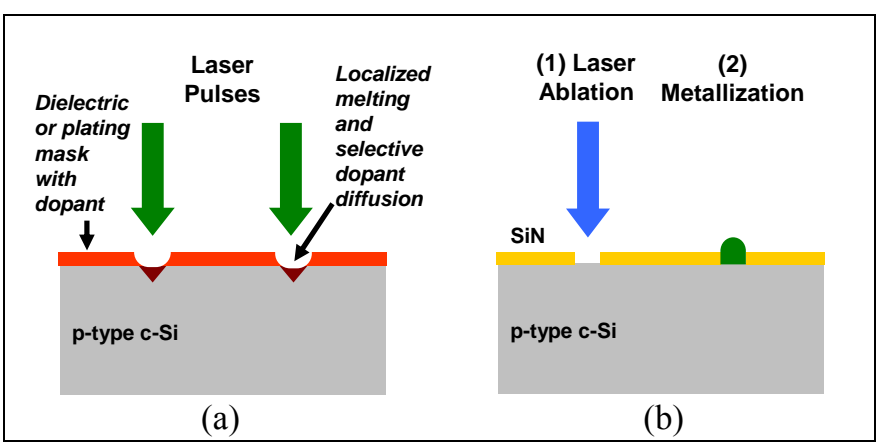

Fig. 9 Selective emitters in c-Si cells. (a) Schematic of laser dopant diffusion (b) Schematic of dielectric ablation.

One method to achieve the SE structure is through laser 
dopant diffusion, see Fig. 9(a). A textured, n-type doped, silicon nitride coated polycrystalline wafer is produced as in conventional cell manufacturing. A thin coating of $n-$ type dopant is then sprayed or spun onto the wafer. A mode-locked (high frequency $>50 \mathrm{MHz}$, low pulse energy $<0.2 \mu \mathrm{J}$ ) or $\mathrm{CW} /$ longer pulse UV or green DPSS laser at $\sim 10 \mathrm{~W}$ is then used to simultaneously melt the dopant, $\mathrm{SiN}$ and silicon at the top surface. This drives the n-type dopant into the melted silicon to form a precise array of narrow $(15 \mu \mathrm{m})$, shallow, highly doped SE lines. Excess dopant is washed off and contacts are then electroplated. Precise control of the doping depth and line widths can be achieved by tuning the laser parameters. The gains achieved by the employment of laser doped SE technology in polycrystalline cells can be significant, with absolute efficiency increases reported from 0.5 to $0.8 \%$ compared with a conventional homogeneous emitter cell [14], [15], [16].

An alternative method uses lasers to ablate local openings in the dielectric $\mathrm{SiN}$ and $\mathrm{SiOx}$ passivation layer on the surface of the wafer without damaging the silicon substrate below, see Fig. 9(b) and Fig. 10(a). Typically UV picosecond pulses are required to ensure low damage to the remaining silicon [17], although promising results have also been shown with green and IR picosecond lasers [18]. Typical processes use single laser shots with several to tens of $\mu \mathrm{J}$ pulse energy depending on laser, layer and substrate properties. As processing costs reduce, the advantages of femtosecond pulses in reduced surface damage may also prove viable for this application [19]. After ablation the passivated cells are metalized to provide a precise array of narrow $(20 \mu \mathrm{m})$ contact lines.

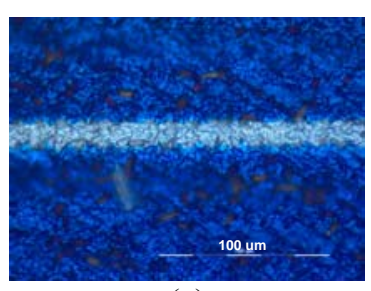

(a)

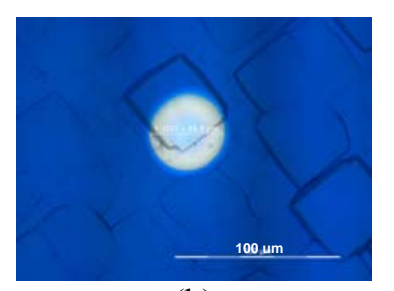

(b)
Fig. 10 Laser selective ablation for (a) selective emitter and (b) rear contact (courtesy of Coherent).

Laser dielectric ablation can also be employed to produce advanced back contacts such as those in IMEC's i-PERC (industrial-passivated emitter and rear cells) HE cell. The i-PERC process focuses on the use of lower cost industrial techniques rather than striving for highest purity HE cells and can compete with conventional aluminiumalloyed back surface field (Al-BSF) cells where aluminium is deposited directly onto the back of the silicon. A comparatively low-quality rear $\mathrm{SiO}_{2} / \mathrm{SiN}$ dielectric is deposited on the rear of the cell using plasma-enhanced chemical vapour deposition (PECVD). The dielectric is laser perforated, see Fig. 10(b), then screen-printed with aluminium which is fired to form local BSF contacts through the perforations. IMEC has reported $18.9 \%$ efficiency in thin multi-crystalline i-PERC silicon solar cells a gain of over $0.8 \%$ absolute over conventional Al-BSF cells [20].

Laser fired contacts (LFC) follow a similar principle to that of the selective emitters produced by dopant diffusion, see Fig. 11. In this case an infra-red nanosecond-pulsed DPSS laser is used to melt and fire p-type aluminium through a passivation layer to form localised contacts several microns deep into the p-type silicon. This process was developed by Fraunhofer ISE [21]. The selectivity of the contacts allows the field back reflector to be tuned and optimized to reflect infra-red light that is not absorbed in a single pass through the cell to further increase efficiency.

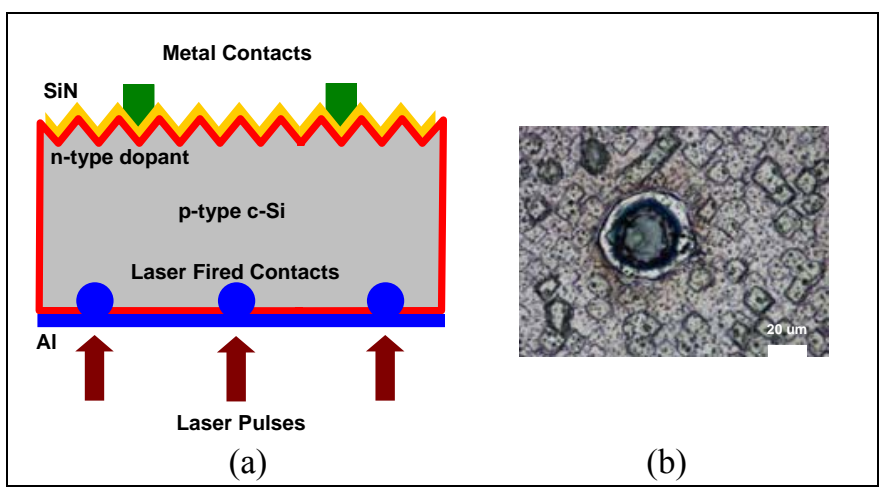

Fig. 11 (a) Schematic and LFC process (b) Photograph of laser fired contact (courtesy of Coherent).

\subsection{Laser drilled 'wrap-through' contacts}

Some HE c-Si cell designs use laser drilled holes to form either emitter wrap-through (EWT) [22] or metal wrap-through (MWT) [23] contacts, see in Fig. 12. These cells use the holes to bring the front contact to the rear side removing some or all of the metallization from the front surface and reducing shadowing losses. This also enables the use of surface-mount methods to provide a high packing density and it reduces resistance losses, both of which enhance efficiency at the module level.

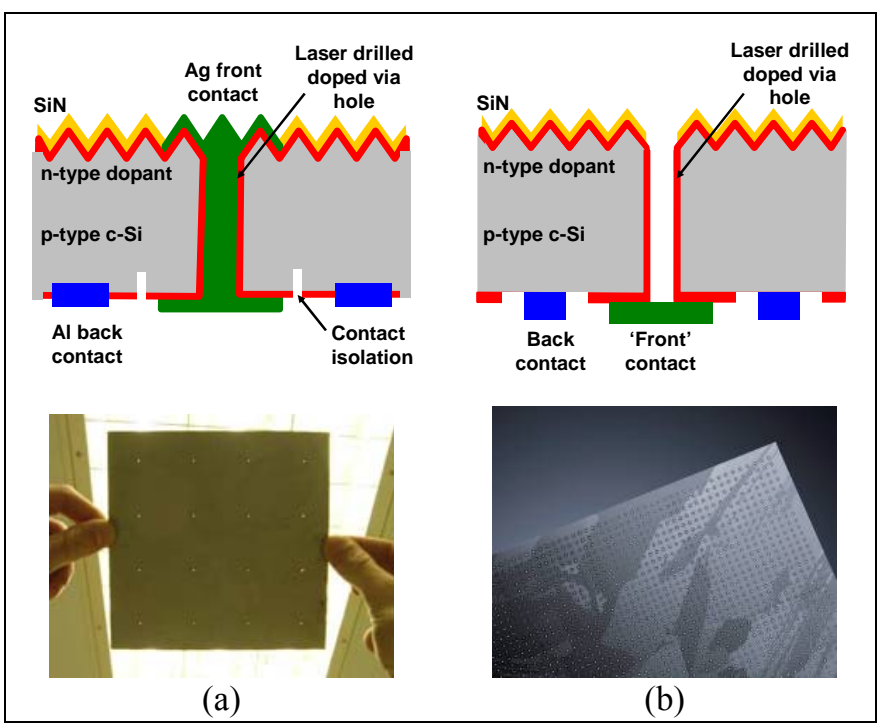

Fig. 12 Wrap through contacts in c-Si cells. (a) Schematic and image of MWT (courtesy of Exitech) (b) Schematic and image of EWT (courtesy of Trumpf).

For MWT cells, infra-red or green pulsed DPSS lasers are used to drill via holes which are subsequently doped and metallized to lead the metal grid structure to the rear side for contacting. Up to 20 holes with greater than $50 \mu \mathrm{m}$ 
diameter are necessary per wafer and this is realizable with a process step of less than 2 seconds.

For EWT cells, an infra-red pulsed DPSS laser, together with a galvo-scanner to give multiple passes of the beam across the wafer, can deliver one laser pulse per hole per pass. Depending on the wafer thickness, over 6 pulses per hole are required to generate a through hole. The holes are then doped with the rest of the wafer wrapping the junction through to the rear and reducing the distance carriers have to travel to be collected. This HE design has no front surface metal; in comparison with conventional cells it has no shadowing losses and improved efficiency. In excess of 10,000 vias of approximately $50 \mu \mathrm{m}$ diameter are required per second.. In both MWT and EWT processes lasers with pulse widths in the range $200 \mathrm{~ns}$ to $1 \mu \mathrm{s}$ and pulse energies of the order of $5 \mathrm{~mJ}$ have been implemented.

\subsection{High-efficiency cells and industrial production}

The theoretical limiting efficiency for c-Si devices is $29 \%$ [24], however 'standard' c-Si solar cell devices have many loss mechanisms and provide typical efficiencies of $14-15 \%$. Losses occur due to light reflection at the front surface and front contacts, light absorption at the back contact, electrical losses due to bulk recombination of carriers and recombination and resistive losses at the contacts. The high-efficiency cell concepts are designed to reduce these losses and bring solar cells closer to the theoretical limiting efficiency.

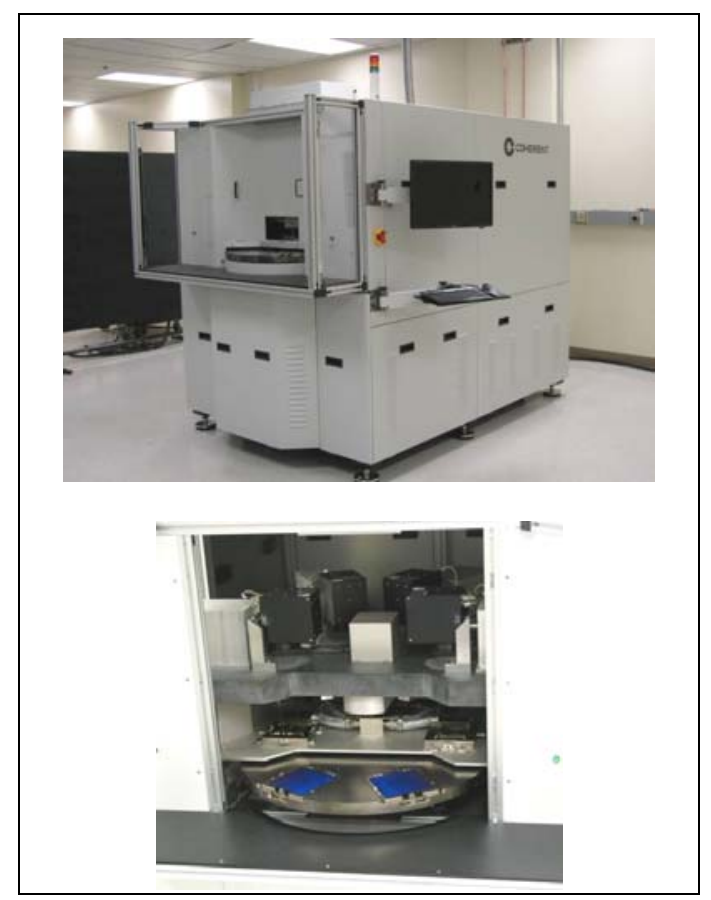

Fig. $13 \mathrm{C}-\mathrm{Si}$ industrial laser processing equipment (courtesy of Coherent).

The highest efficiencies on silicon have been achieved on monocrystalline cells. The highest commercial efficiency is produced by SunPower at over $19.5 \%$ at the module level [25] and with a record cell at $24.2 \%$ [26]. Their backside contacted cell uses expensive, high-quality silicon wafers and multiple patterning steps to produce the interdigitated contacts. The University of New South Wales has achieved $25 \%$ efficiency on monocrystalline silicon with its PERL (passive emitter and rear locally diffused) cell [27]. However, it is still a challenge to engineer a solution for manufacturing in low-cost high-volume production lines on poly-crystalline silicon. The SE cells described in section 3.3 are the closest to wide-scale production. The $\mathrm{SE}$ alone on front of standard c-Si cell types can improve the absolute efficiency by $0.8 \%$. The implementation of SE technology alongside additional improvements, such as improved passivation and metallization technologies can realize up to $2 \%$ gains in absolute efficiency. This would bring 'conventional' production well above the 14-15\% levels typical for today.

The other HE technologies such as LFC, MWT, EWT and selective rear contacts are not prevalent in industrial production today. However future thinning of wafers to below $180 \mu \mathrm{m}$ means that today's high-temperature and contact-based methods will need to be improved upon to reduce the risk of yield losses though warpage and breakage. This opens the door for the additional laser process steps as a route to improve yield as well as enhanced efficiency.

The availability of industrial laser sources suitable for the c-Si cell production processes has enabled the widespread adoption of laser edge isolation and increasing adoption of HE cell production laser processes. A typical example of a laser-based production tool for $\mathrm{c}-\mathrm{Si}$ wafers is shown in Fig. 13.

\section{Laser processing contribution to cost reduction}

Today's production costs for thin-film silicon modules are approximately $1-1.2 \$ / \mathrm{Wp}$ and the laser processing of a thin-film silicon module constitutes under $4 \%$ of the cost of production. For an a-Si panel with 159 cells, reducing the laser scribe dead zone from $500 \mu \mathrm{m}$ to $240 \mu \mathrm{m}$ provides a $4 \%$ increase in module power and hence in fab output. This process improvement pays for all of the laser processes in the line. With its ability to provide effective processing, it is clear why laser processing is the method of choice for industrial production in thin-film PV.

Today's production costs for c-Si modules are approximately $1.4-1.8 \$ / \mathrm{Wp}$ and are predicted to fall to $1 \$ / \mathrm{Wp}$ in 2010 [2]. Laser processes in c-Si manufacturing enable HE cell designs, such as selective emitters and enhanced contacts providing up to $2 \%$ increase in absolute efficiency. As these processes can be incorporated in existing production lines with similar cost of ownership to conventional cell production, the efficiency improvement pays for the laser processes. It is no surprise that a significant number of cell producers are evaluating the incorporation of laser enhancement steps to their production.

\section{Summary and Outlook}

Laser processes efficiently perform important steps in PV cell manufacturing. Laser systems are proven in industrial production with lasers used for patterning and edge isolation for all thin-film PV technologies and for edge isolation scribing, grooving, contact vias and emitter doping for c-Si technologies. Where laser processes have been adopted in production they exploit the advantages of selec- 
tive machining, a well defined interaction region, high precision and cost effective processing. In the mission of the solar industry to reduce the cost of electricity generation there are increasing opportunities for laser processing to contribute to the goal of low cost of ownership in industrial manufacturing through improved module efficiencies, higher throughput and reduced process costs. Although 'standard' c-Si cell designs characterized by discrete front and back contacts deposited via screen-printing and firing constitute over $90 \%$ of c-Si cell production today, the enhanced efficiency cells utilizing laser technologies are becoming more widely produced and will grow in market share in the years to come. In thin-film PV the adoption of lasers for CIS/CIGS for P2 and P3 scribing is also imminent.

The most significant contribution of laser processing to cost down of PV module manufacturing is increased efficiency through maximized active area and efficient current collection. In thin-film PV, high accuracy laser processing provides reduced scribe dead zone. In c-Si PV laser processing enables production of HE cell devices. In summary there is high potential for laser processing in industrial PV module manufacturing to deliver increased efficiencies and laser technology is well placed to support the solar industry's roadmap.

\section{Acknowledgments}

I would like to thank Finlay Colville from Solarbuzz for useful discussions and Dave Clark (Coherent), Jörg Jetter (4-Jet) and Christof Siebert (Trumpf) for providing material used in this paper.

\section{References}

[1] P. Mints, "Photovoltaic Manufacturer Shipments, Capacity \& Competitive Analysis 2009/2010", Navigant Consulting, April (2010)

[2] S. Mehta, "Greentech Media Research, Thin-film 2010: Market Outlook to 2015", March, (2010)

[3] Solarbuzz, from 'DS_Q2'10 Quarterly PV Cell Capacity Database \& Trends Report", June, (2010)

[4] F. Coleville, "PV's 20/20 Vision Demands CostEfficiency Duality", PV Society, December 10, (2009)

[5] F.A. Borgeson, J.J. Hanak, R.S. Harju, N.L. Helman, and K.R. Hecht, "Method and apparatus for laser scribing glass sheet substrate coatings", U.S. Patent 2003029848, (2001)

[6] H. Huber, M. Englmaier, C. Hellwig, G. Heise, M. Kemnitzer, T. Kuznicki, C. Menhard, R. Brenning, A. Heiss, H. Vogt, J. Palm, "Picosecond laser structuring for the monolithic serial interconnection of CIS solar cells", 24th EUPVSEC, Hamburg, p.3066, (2009)

[7] F. Colville, C. Dunskey and J. Hopkins, "Existing and emerging laser applications within PV Manufacturing", Photovoltaics International, August, (2008)

[8] M. Acciarri, F. Lusso, M. Caldironi, S. Pellegrino, "Multi-crystalline silicon solar cells laser edge isolation: a comparison of process results achieved with state-of-the-art tripled Nd:YAG and fiber lasers", 23rd EUPVSEC, Valencia, p.1837, (2008)

[9] S. Wenham and M. Green, "Buried Contact Solar Cells," Australian Patent 570309, (1985)
[10]N. Mason et al., "High Efficiency Silicon Solar Cell Production Technology", 10th EUPVSEC, Lisbon (1991)

[11] O. Schultz, S.W. Glunz, W. Warta, R. Preu, A. Grohe, M. Köber, G.P. Willeke, R.Russel, J. Fernandez, C. Morilla, R. Bueno and I. Vincuería, "High-efficiency solar cells with laser-grooved buried contact front and laser-fired rear for industrial production", $21^{\text {st }}$ EUPVSEC, Dresden (2006)

[12]B. Raabe, H. Haverkamp, F. Book, A. DastgheibShirazi, R. Moll, G. Hahn, "Monocrystalline silicon future cell concepts", $22^{\text {nd }}$ EUPVSEC, Milan, (2007)

[13]F. Colville, "Laser-Assisted Selective Emitters and the Role of Laser Doping", Photovoltaics International, 5, 84, September (2009)

[14] U. Jäger, M. Okanovic, M. Hörtheis, A. Grohe and R. Preu, "Selective emitter by laser doping from phosphosilicate glass", 24th EUPVSEC, Hamburg, p1740, (2009)

[15] J. R. Köhler, P. Grabitz, S. J. Eisele, T. C. Röder, J. H. Werner, "Laser doped selective emitters yield $0.5 \%$ efficiency gain", 24 ${ }^{\text {th }}$ EUPVSEC, Hamburg, p.1847 (2009)

[16] M. Gauthier, M. Grau, O. Nichiporuk, F. Madon, V. Mong-The Yen, N. Le Quang, A. Zerga, A. Slaoui, D. Blanc-Pélissier, A. Kaminski, M. Lemiti, "Industrial approaches of selective emitter on multicrystalline silicon solar cells", 24th EUPVSEC, Hamburg, p1875, (2009)

[17] V. Rana, Z. Zhang, C. Lazik, R. Mishra, T. Weidman, C. Eberspacher, "Investigations into selective removal of silicon nitride using laser for crystalline silicon solar cells", 23rd EUPVSEC, Valencia, p. 1942, (2008)

[18] S. Hermann, T. Neubert, B. Wolpensinger, N.-P. Harder, R. Brendel, "Process characterisation of picosecond laser ablation of $\mathrm{SiO}_{2}$ and $\mathrm{SiN}_{\mathrm{x}}$ layers on planar and textured surfaces", 23rd EUPVSEC, Valencia, p. 1204, (2008)

[19] K. Stolberg, S. Friedel, B. Kremser, M. Leitner, Y. Atsuta, "Ablation of Ablation of SiN passivation layers on photovoltaic cells with femtosecond laser source", 5th LAMP, Kobe, (2009)

[20] N.E. Posthuma, T. Janssens, E. Van Kerschaver, P. Choulat, X. Loozen, Y. Ma, J. John, G. Beaucarne and J. Poortmans, "Development of high efficiency FZ silicon solar cells by application of the i-PERC concept", 24th EUPVSEC, Hamburg, p1600, (2009)

[21] E. Schneiderlöchner, R. Preu, R. Lüdemann, and S. W. Glunz, "Laser-fired rear contacts for crystalline silicon solar cells", Progr. Photovolt., 10, p. 29-34 (2002)

[22]P. Hacke, B. Murphy, D. Meakin, J. Dominguez, J. Jaramillo, M. Yamasaki, J. Gee, "Busbarless emitter wrap-through solar cells and modules", 33rd IEEE PVSC, San Diego, CA (2008)

[23] C.J.J. Tool, G. Coletti, F.J. Granek, J. Hoornstra, M. Koppes, E.J. Kossen, H.C. Rieffe, I.G. Romijn, A.W. Weeber," "17\% mc-Si solar cell efficiency using full in-line processing with improved texturing and screenprinted contacts on high-ohmic emitters", 20th EUPVSEC, Barcelona, (2005)

[24] M.A. Green, "Third generation photovoltaics: solar 
cells for 2020 and beyond", Physica E: Lowdimensional Systems and Nanostructures, 14, p.65 (2002)

[25]B. Von Roedern, "Spec sheet table of best commercial modules, 02/2010 version", posted $3^{\text {rd }}$ February, http://www.nrel.gov/pv/thin_film/docs/By_Techn0210 .xls (2010)

[26] Sunpower Corp., "SunPower announces new world record solar cell efficiency", posted $23^{\text {rd }}$ June, http://investors.sunpowercorp.com/releases.cfm (2010)

[27] UNSW "Highest Silicon Solar Cell Efficiency Ever Reached", ScienceDaily, October 24 (2008)

(Received: June 25 , 2010, Accepted: November 04, 2010) 